\title{
PENATALAKSANAAN BENDUNGAN ASI PADA IBU MENYUSUI DENGAN MENGGUNAKAN KOMPRES DAUN KUBIS DI BPM ERNITA PEKANBARU TAHUN 2020
}

\author{
RIKA ANDRIYANI, AULIA ASKA
}

\begin{abstract}
Dams of breast milk can occur due to the narrowing of the lactiferous ducts in the mother's breast and can also occur if the mother has nipple disorders such as flat and sunken, sunken nipples. To reduce breast swelling in a non-pharmacological way, it can be done by compressing the cabbage leaves. Cabbage contains the amino acid glutamine, which is believed to treat all types of inflammation, one of which is inflammation of the breasts. Cabbage is also rich in sulfur content which is believed to reduce breast engorgement and inflammation. The purpose of this final project is to carry out comprehensive and continuous midwifery care for breastfeeding mothers with breastfeeding by using a cabbage leaf compress through a midwifery management approach as well as documenting the care that has been given by the SOAP method. Implementation methods with case studies and case taking were carried out at BPM Ernita on 19-20 September 2020. Care was carried out by conducting a thorough assessment with $N Y$ so that the diagnosis of P1AOH1 postpartum day 9 with Asi Dam was confirmed. The plan is based on a diagnosis, namely giving cabbage leaves compresses to mothers and providing health education about breastfeeding techniques and breast care. The results obtained after doing midwifery care on Mrs. ASI dam complaints can be resolved.
\end{abstract}

Key word: Maternal Midwifery Care, Cabbage Leaves

\begin{abstract}
ABSTRAK
Bendungan ASI dapat terjadi karena adanya penyempitan duktus laktiferus pada payudara ibu dan dapat terjadi pula bila ibu memiliki kelainan puting susu misalnya putting susu datar dan terbenam, cekung. Untuk mengurangi pembengkakan payudara secara non farmakologis dapat dilakukan dengan kompres daun kubis. Kubis mengandung asam amino glutamine yang diyakini dapat mengobati semua jenis peradangan, salah satunya radang yang terjadi pada payudara. Kubis juga kaya akan kandungan sulfur yang diyakini dapat mengurangi pembengkakan dan peradangan payudara. Tujuan tugas akhir ini adalah untuk melaksanakan asuhan kebidanan secara menyuluruh dan berkesinambungan pada ibu menyusui dengan bendungan asi dengan menggunakan kompres daun kubis melalui pendekatan manajemen kebidanan serta mendokumentasikan asuhan yang telah diberikan dengan metode SOAP. Metode pelaksanaan dengan studi kasus dan Pengambilan kasus dilakukan di BPM Ernita pada tanggal 19-20 september 2020. Asuhan dilakukan dengan melakukan pengkajian secara menyeluruh dengan NY sehingga dapat ditegakkan diagnosis $\mathrm{P}_{1} \mathrm{~A}_{0} \mathrm{H}_{1}$ Nifas hari ke 9 dengan Bendungan Asi. Plan disusun berdasarkan diagnosis yakni memberikan kompres daun kubis kepada ibu serta memberikan pendidikan kesehatan tentang teknik menyusui dan perawatan payudara. Hasil yang didapatkan setelah melakukan asuhan kebidanan pada Ny keluhan bendungan ASI dapat teratasi.
\end{abstract}

\section{Kata Kunci : Asuhan kebidanan ibu Nifas, Daun Kubis}




\section{PENDAHULUAN}

Masa nifas (puerperium) dimulai setelah plasenta lahir dan berakhir ketika alat-alat kandungan kembali seperti keadaan sebelum hamil. Masa nifas berlangsung selama kira- kira 6 minggu atau 42 hari, namun secara keseluruhan akan pulih dalam waktu 3 bulan (Wilujeng and Hartati, 2018)

Auhan selama periode menyusui perlu mendapat perhatian karna sekitar 60\%angka kematian ibu terjadi.Angka kematian ibu (AKI) adalah banyaknya wanita yag meninggal dari suatu penyebab kematian terkait dengan gangguan kehamilan atau penangannya (tidak termasuk kecelakaan atau kasus insidentil) selama kehamilan, melahirkan dan dalam masa nifas (42 hari setelah melahirkan) tanpa memperhitungkan lama kehamilan per 100.000 kelahiran hidup (Wahyuni, 2018).

Salah satu masalah yang sering dialami pada masa nifas adalah Pembengkakan payudara. Mastitis adalah infeksi yang disebabkan adanya sumbatan pada duktus (saluran susu) hingga putting susu atau disebut juga peradangan pada payudara.Bendungan asi adalah penyempitan pada saluran ASI yang disebabkan karna air susu mengental sehingga menyumbat lumen saluran (Khasanah and Sulistyawati, 2017).

Bendungan ASI dapat terjadi karena adanya penyempitan duktus laktiferus pada payudara ibu dan dapat terjadi pula bila ibu memiliki kelainan putting susu misalnya putting susu datar dan terbenam, cekung. ASI yang menumpuk pada payudara bila tidak dikeluarkan menyebabkan payudara membengkak dan aerola mamae menjadi lebih menonjol, puting lebih datar dan susah diisap bayi.

Peran bidan sangat penting memberi tahu ibu untuk memberikan ASI kepada bayinya karena ASI bisa memberi kekebalan tubuh, serta sangat baik untuk pertumbuhan dan perkembangan bayi karena dalam penelitian dijumpai kenyataan bahwa terjadi banyak penyulit pada bayi yang sejak awal mempergunakan susu formula yaitu terjadinya penyakit diare dan tumbuhkembang yang kurang memuaskan. Dan peran ibu maupun masyarakat bisa mencegah terjadinya infeksi payudara, karena yang selama ini terjadi masyarakat masih menganggap bahwa perawatan payudara itu kurang penting (Nurliana Mansyur and A. Kasrinda Dahlan, 2014)

Untuk mengurangi pembengkakan payudara secara non farmakologis dapat 
dilakukan dengan kompres kubis. Kubis atau kol (Brassica Oleracea Var. Capitata) merupakan sayuran ekonomis yang sangat mudah ditemukan. Kubis . mengandung asam amino glutamine yang diyakini dapat mengobati semua jenis peradangan, salah satunya radang yang terjadi pada payudara. Kubis juga kaya akan kandungan sulfur yang diyakini dapat mengurangi pembengkakan dan peradangan payudara(Apriani, Wijiyanti and Widyastutik, 2018)

Pengaruh kompres daun kubis (Brassica Oleracea Var. Capitata) terhadap pembengakakan payudara pada ibu nifas. Berdasarkan tabel 5.6 diatas bahwa sebelum diberikan kompres daun kubis (Brassica Oleracea Var. Capitata) seluruh responden $\quad(100 \%) \quad$ mengalami pembengakkan payudara,setelah diberikan kompres daun kubis diketahui bahwa responden hampir seluruhnya $(91 \%)$ tidak mengalami pembengkakan payudara, sebagian $\quad$ kecil $(9 \%)$ mengalami pembengkakan payudara (Widia and Pangestu, 2020).

Berdasarkan survey yang dilakukan oleh penulis BPM Ernita,1 dari $20 \mathrm{ibu}$ menyusui selama 1 bulan terakhir yang melahirkan di BPM dengan keluhan bendungan asi. Oleh karna itu, penulis tertarik untuk memberikan asuhan dausah daun kubis guna memperkecil pembekakan payudara yang disebabkan oleh bendungan asi.

\section{METODOLOGI KASUS}

Metode laporan ini adalah studi kasus dengan latar belakang asuhan kebidanan pada Ibu menyusui Dengan Bendungan ASI menggunakan Kompres Daun Kubis Pengambilan kasus dilakukan di BPM Ernita pada tanggal 19-20 september 2020. Intrumen yang digunakan berupa panduan anamnesis, formulir pemantaun dan alat yang digunakan Spignanometer, daun kubis, baskom, tisu dan stopwatch. leaflet untuk konseling yang digunakan, menyiapkan kamera pendokumentasian.

\section{HASIL}

\section{A. KUNJUNGAN PERTAMA}

Kajian $\mathrm{n}$ pertama dilakukan pada Ny R pada tanggal 19 September 2020 pukul 11.00 wib, Data subjektif Ny. R usia 27 tahun, anak pertama, baru selesai melahirkan 9 hari yang lalu, Ibu mengeluh paayudara terasa nyeri dan keras, Seperti yang dikatakan ibu " Keluhannya payudara saya dua duanya terasa nyeri dan tegang, penuh rasanya” . dan Bayi sering tidur dan menyusu saat bangun saja “ anak saya baik laku, tidur saja jadi menyusu nya kalau bangun aja “. 
Riawayat kelahiran bayi normal " bayi saya lahir normal BB $2800 \mathrm{gr}$ PJ $48 \mathrm{~cm}$ pas lahir nangisnya kencang "

Pada Pengumpulan data Objektif peneliti melakukan pemeriksaan kepadsa pasien ditemukan Keadaan emosional Stabil, Keadaan umum Baik, Tekanan Darah 120/80 MmHg,Suhu

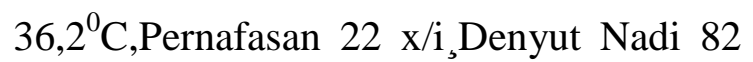
$\mathrm{x} / \mathrm{i}$, Payudara teraba keras, hangat, nyeri saat diraba, Putting Susu Menonjol, Pengeluaran ASI (+), TFU tidak teraba, lochea alba, oedem pada kaki (-). Dari hasil pengkajian data diatas dapat ditarik analisa $\mathrm{NY} \quad \mathrm{R} \quad \mathrm{P}_{1} \mathrm{~A}_{0} \mathrm{H}_{1}$ Nifas hari ke 9 dengan Bendungan Asi

\section{B. KUNJUNGAN KEDUA}

\section{$\underline{\text { Kajian kedua }}$}

Pada kajian ini pada hari selasa tanggal 21 September 2020, dilakukan di rumah pasien jalan teropong arengka, Kota Pekanbaru Provinsi Riau pukul 10.00 wib. Ibu mengatakan bayi sudah sering menyusui, payudara sudah tidak nyeri lagi, ibu melakukan kompres daun kubis 3x sehari saat saat payudara tegang dan nyeri. Seperti yang dikatakan ibu “ alhamdulillah, payudara saya sudah tidak nyeri dan tegang lagi, bayi sudah sering menyusui “. Ibu melakukan semua pendidikan kesehatan yang diberikan, “ Semua yang adek sampaikan kemarin saya ikuti, kalo anak saya tidur kelamaan saya bangungkan, teknik menyusui sudah sperti yang diajarkan”

Pada pengumpulan data Objektif, ditemukan data yaitu Keadaan umum Baik, Tekanan Darah 120/80 MmHg,Suhu $36,2^{0} \mathrm{C}$,Pernafasan $22 \mathrm{x} / \mathrm{i}_{\text {s Denyut Nadi } 82}$ $\mathrm{x} / \mathrm{i}_{\text {s}}$ Payudara lunak (baru selesai menyusui) tidak ada nyeri raba, Bayi menyusu kuat ,TFU tidak teraba, lochea alba, oedem pada kaki (-). Berdasarkan pengkajian data dapat ditarik analisa $\mathrm{P}_{1} \mathrm{~A}_{0} \mathrm{H}_{1}$ Nifas hari ke 1I dengan keadaan umum ibu baik

\section{PEMBAHASAN}

Pada kunjungan pertama, ditemukan keluhan yang dialami Ny. $\mathrm{R}$ adalah payudara tegang dan terasa nyeri. Menurut (Wilujeng and Hartati, 2018) Gejala yang sering muncul pada saat terjadi bendungan ASI antara lain payudara bengkak, payudara terasa panas. Kurangnya ibu memberikn ASI pada bayi nya, cara menyusui yang kurang tepat, produksi ASI meningkat, terlambat menyusukan, hubungan dengan bayi (bonding) kurang baik, dan dapat pula karena adanya pembatasan waktu menyusui yang dapat menyebabkan pembengkakan payudar. 
Hal ini juga didapatkan saat melakukan anamnesa dengan $\mathrm{Ny} \mathrm{R}$, bahwa jarang menyusui bayinya lebih membiarkan bayi tidur, dan juga masih bingung dengan proses menyusui.

Berdasarkan hasil pengumpulan data pada kasus NY $\mathrm{R}$ ibu dinyatakan mengalami bendungan ASI Menurut teori (Khasanah and Sulistyawati, 2017) bendungan ASI disebabkan karena air susu yang terkumpul tidak dikeluarkan sehingga menjadi sumbatan. Gejala yang sering muncul pada saat terjadi bendungan ASI antara lain payudara bengkak, payudara terasa panas. Penatalaksanaan yang dilakukan penulis yaitu dengan pengompresan daun kubis. Daun kubis merupakan terapi non farmakologis untuk pencegahan bendungan ASI.

Penatalaksanaan kasus berdasarkan masalah yang ditemui adalah mengajarkan kepadai ibu untuk melakukan kompes daun kubis pada payudara yang terasa nyeri dan bengkak tersebut Tujuan nya adalah untuk mengurangi pembengkakan payudara, apabila perawatan payudara dengan kompres daun kubis dilakukan dengan baik maka pembengkakan payudara akan berkurang. Hal ini sudah sesuai dengan hasil penilitian yang dilakukan oleh (Damayanti, Ariani and Agustin, 2020) diketahui bahwa pemberian kompres daun kubis dingin dan juga perlakuan perah ASI pada responden mampu memberikan efek yang baik dalam menurunkan skala pembengkakan dan intensitas nyeri payudara, serta meningkatkan jumlah ASI. Hasil uji Wilcoxon untuk ketiga variabel (skala pembengkakan, intensitas nyeri, dan jumlah ASI) antara nilai sebelum dan sesudah diberikan perlakuan pada kelompok kompres daun kubis dingin menunjukkan nilai p-value untuk penurunan skala pembengkakan sebesar 0,000, p-value untuk penurunan intensitas nyeri sebesar 0,000 , dan $p$-value untuk peningkatan jumlah ASI adalah 0,000. Sedangkan pada kelompok kontrol didapatkan nilai $p$-value dari ketiga variabel pada kedua kelompok tersebut adalah $<\alpha(0,05)$. Hal ini membuktikan bahwa terdapat perbedaan yang signifikan pada ketiga variabel antara nilai sebelum dan sesudah pemberian perlakuan pada kedua kelompok.

Cara penggunaan kompres kubis yang benar yang dapat mengurangi peembengkakan payudara adalah yaitu Daun kubis dimasukkan ke dalam lemari pendingin selama 20-30 menit, lalu mengompreskan daun kubis dingin pada payudara ibu hingga menutupi seluruh 
permukaan payudara, selama 30 menit, perlakuan ini dilakukan sebanyak 3 kali dalam sehari selama 2 hari. kubis. Kubis atau kol (Brassica Oleracea Var. Capitata) merupakan sayuran ekonomis yang sangat mudah ditemukan. Kubis . mengandung asam amino glutamine yang diyakini dapat mengobati semua jenis peradangan, salah satunya radang yang terjadi pada payudara. Kubis juga kaya akan kandungansulfur yang diyakini dapat mengurangi pembengkakan dan peradangan payudara (Apriani, Wijiyanti and Widyastutik, 2018).

Penatalaksanaan bendungan ASI selanjutnya adalah mengajarkan kepada ibu tentang proses menyusui, menurut Wahyuni, 2018 bahwa untuk menjaga produksi ASI agar tetap baik maka pemberian ASI pada bayi secara on demand dan minimal 2 jam sekali harus disusui. Saat menyusui payudara harus dikosongkan secara menyeluruh sehingga dapat meningkatkan kan taraf produksi ASI

Penatalaksanaan Bendungan ASI selanjutnya, penulis menganjurkan ibu untuk mencukupi kebutuhan cairan dengan minum 9 gelas air mineral dalam sehari, mengomsumsi makanan yang bergizi dan menyehatkan, mencukupi pola tidur yang baik sekitar 7 hingga 8
jam,Susuin terus bayi, hindari stress dan banyak pikiran.

Pada kunjungan kedua, rasa nyeri pada payudara ibu sudah berkurang. Asuhan yang diberikan kepada ibu di kunjungan pertama telah berhasil masalah ibu dapat diatasi. Hal ini sudah sesuai dengan hasil penulitian yang dilakukan oleh (Damayanti, Ariani and Agustin, 2020) diketahui bahwa pemberian kompres daun kubis dingin dan juga perlakuan perah ASI pada responden mampu memberikan efek yang baik dalam menurunkan skala pembengkakan dan intensitas nyeri payudara, serta meningkatkan jumlah ASI.

\section{KESIMPULAN}

Asuhan Kebidanan Pada Ibu Nifas dengan bendungan ASI menggunakan kompres daun kubis di BPM Ernita dilaksanakan pendekatan manajemen varney dan didokumentasikan dengan metode SOAP. Pengkajian data dilakukan secara lengkap, akurat dan relevan dengan masalah yang dihadapi pasien, dan berdasarkan pengkajian maka analisa nya NY R $\quad \mathrm{P}_{1} \mathrm{~A}_{0} \mathrm{H}_{1}$ Nifas hari ke 9 dengan Bendungan Asi. Pemberian kompres daun kubis, pemberian informasi tentang kapan bayi harus menysui dan mengajarkan teknik menyusi serta nutrisi selama nifas 
merupakan penatalaksanaan yang dilakukan untuk mengatasi masalah bendungan ASI. Masalah bendungan ASI dapat teratasi, saat melakukan kunjungan kedua, pasien tidak lagi mengeluh dengan payudara nya.

\section{SARAN}

Diharapkan dapat meningkatkan manajemen asuhan kebidanan yang diterapkan terhadap pasien dalam memberikan KIE tentang perawatan payudara selama ANC dan memasang poster tentang sukses menyusui dan dapat mengatasi masalah pada payudara ibu nifas terutama ibu nifas dengan bendungan ASI

\section{DAFTAR PUSTAKA}

Apriani, A., Wijiyanti and Widyastutik, D. (2018) 'Efektivitas Penatalaksanaan Kompres Daun Kubis (Brassica Oleracea Var. Capitata) Dan Breast Care Terhadap Pembengkakan Payudara Bagi Ibu Nifas', Efektivitas Penatalaksanaan Kompres Daun Kubis (Brassica Oleracea Var. Capitata) Dan Breast Care Terhadap Pembengkakan Payudara Bagi Ibu Nifas, II(4), pp. 238-243.
Damayanti, E., Ariani, D. and Agustin, D. (2020) 'Pengaruh Pemberian Kompres Daun Kubis Dingin sebagai Terapi Pendamping Bendungan ASI terhadap Skala Pembengkakan dan Intensitas Nyeri Payudara serta Jumlah ASI pada Ibu Postpartum di RSUD Bangil', Pengaruh Pemberian Kompres Daun Kubis Dingin sebagai Terapi Pendamping Bendungan ASI terhadap Skala Pembengkakan dan Intensitas Nyeri Payudara serta Jumlah ASI pada Ibu Postpartum di RSUD Bangil, 4, pp. 54-66. doi: 10.21776/ub.JOIM.2020.004.02.1.

Khasanah, N. A. and Sulistyawati, W. (2017) 'Buku Ajar Nifas Dan Menyusui', In Perdana, R. (Ed.) Buku Ajar Nifas Dan Menyusui. 1st Edn. Surakarta: Kekata Publisher, Pp. 1176. Available At: https://scholar.google.co.id/scholar?h l=id\&as_sdt $=0 \% 2 \mathrm{C} 5 \& \mathrm{q}=\mathrm{jurnal}+\mathrm{artik}$ el+ilmiah\&btnG $=$.

Megasari, M. et al. (2019) Catatan SOAP sebagai dokumentasi legal dalam pratik kebidanan, Nuha Medika. Edited by J. . MEITHA. Pekanbaru: Nuha Medika. doi: 10.1055/s-2008- 
1040325.

Nurliana Mansyur, S. S. and A. Kasrinda Dahlan, S. S. (2014) 'Buku Ajar Asuhan Masa Nifas', in Nurliana Mansyur, S. S. and A. Kasrinda Dahlan, S. S. (eds) Asuhan Kebidanan Masa Nifas. 1st edn. jawa timur: perpustakaan nasional, pp. 1146.

doi:

10.1017/CBO9781107415324.004.

Wahyuni, E. dwi (2018) 'Asuhan kebidanan nifas dan menyusui', in Utami, S. (ed.) Asuhan kebidanan nifas dan menyusui. 1st edn. jakarta: kementrian kesehatan republik indonesia, pp. 1-286.

Widia, L. and Pangestu, delia ayu putri (2020) 'Pengaruh Kompres Daun Kubis (Brassica Oleracea Var.
Capitata) Terhadap Pembengkakan Payudara (Breast Engorgement) Pada Ibu Nifas', Pengaruh Kompres Daun Kubis (Brassica Oleracea Var. Capitata) Terhadap Pembengkakan Payudara (Breast Engorgement) Pada Ibu NifaS, 8(1), pp. 45-51.

Wilujeng, R. D. and Hartati, A. (2018) 'Buku Ajar Asuhan Kebidanan Nifas', Akademi Kebidanan Griya Husada Surabaya, p. 82. 